\title{
A PERSPECTIVA DA MENORIDADE PENAL E SUA IMPLICAÇÃO NA SOCIEDADE CONTEMPORÂNEA
}

\author{
THE PROSPECT OF CRIMINAL MINORITY AND ITS IMPLICATION IN CONTEMPORARY SOCIETY
}

DOI: 10.16891/2317-434X.v8.e1.a2020.pp380-387

Recebido em: 01.08.2019 / Aceito em: 28.08.2019

\section{Pedro Henrike Vereda Barbosa*a, Carlos Eduardo Franca Pereira}

Centro Universitário Doutor Leão Sampaio - UNILEÃOa E-mail: pedrohenrikebarbosa@gmail.com

\section{RESUMO}

A tônica sobre a aprovação da menoridade penal é bem atual, e gera grandes divergências acerca da temática em análise, de forma que o questionamento sobre sua real aplicação sempre está em pauta tendo em vista a incidência de praticas delituosas produzidas por menores de idade. No que concerne à temática central, o referido artigo tem como alvo a menoridade penal, e objetiva proporcionar um debate sobre a real aplicação e eficácia de tal fenômeno, promovendo a percepção de questões que são relevantes para a assimilação e para o debate desse ponto em evidência. O presente trabalho trata-se de uma pesquisa bibliográfica de origem qualitativa, explicativa e exploratória, onde se busca trazer novas discussões acerca da menoridade penal e suas variantes, relacionando questões de ordem sociais que facilitam a explanação das ideias, e a compreensão do objeto em destaque. Da mesma forma, apresenta posições de autores consolidados, e oportuniza a aproximação de ideias que possibilitam a construção lógica, e a devida racionalização da abordagem da menoridade penal, e sua implicação no contexto social vigente.

Palavras-chave: Menoridade Penal; Sociedade; Reflexão.

\section{ABSTRACT}

The tonic on the approval of the criminal minority is very current, and generates great divergences about the thematic in analysis, so that the questioning about its real application is always in the agenda with the aim of the incidence of criminal practices produced by minors. As far as the central theme is concerned, this article targets the criminal lesser, and aims to provide a debate on the real application and effectiveness of such a phenomenon, promoting the perception of issues that are relevant to the assimilation and to the debate of this Point in evidence. The present work is a bibliographical research of qualitative, explanatory and exploratory origin, where it seeks to bring new discussions about the criminal lesser and its variants, relating social issues that facilitate the explanation Of the ideas, and the understanding of the object highlighted. Similarly, it presents positions of consolidated authors, and $A B T T$ the approximation of ideas that enable logical construction, and the proper rationalization of the approach of criminal lesserness, and its implication in the social context in force.

Keywords: Criminal Minority; Society; Reflection. 


\section{INTRODUÇÃO}

Diante da ampla publicitação e exposição de práticas criminosas envolvendo menores de idade, e os desdobramentos que tais atos provocam na esfera social, alavancou-se na contemporaneidade, um sentimento de perplexidade social, de forma tão contundente, a se pensar em medidas muitas vezes radicais no que se refere à menoridade penal. Como não poderia ser diferente, tal discussão gera grande debate sobre o tema e sua real aplicação, o que não menos óbvio, divide a sociedade nos que desejam a aprovação de tal medida, argumentando que haverá uma diminuição nos índices de violência; e em contrapartida, os que são contra, expondo que a aprovação na prática, não gera efeitos, mascarando a inércia dos parlamentares, e de pessoas que se aproveitam do calor das circunstâncias para impor medidas radicais. A falta de perspectiva de vida e de oportunidades deixam os jovens a mercê da criminalidade; $\mathrm{E}$ a lacuna que o estado deixa na realidade desses jovens, é preenchida por praticas ilícitas que afrontam os preceitos sociais.

Então o que impulsionou a produção desse trabalho, foi entender que a menoridade penal é uma questão importante, e que deve ser amplamente debatida, e essa conversação pode ser facilitada através da apresentação de conceitos, definições e ferramentas necessárias às decisões de manutenção e/ou alteração da idade mínima de responsabilização criminal para quem pretende entender essa questão com base na apresentação de ideias e questionamentos embasados em pesquisas bibliográficas, e na explanação de pontos e estratégias ligadas diretamente a menoridade penal.

$\mathrm{O}$ debate sobre as questões relacionadas à menoridade penal no que diz respeito aos moldes atuais, encontra-se bem intricado, haja vista que o tema encontrase rodeado de incertezas em razão de não haver seguridade, ou bases, que assegurem de forma efetiva, que a devida aprovação trará as benesses que são almejadas. Diante de todos os acontecimentos que envolvem menores de idade, é importante que haja mudanças na aplicação das leis, mas o efetivo combate às desigualdades poderá ser uma ferramenta mais eficaz, e que oferta em um curto espaço de tempo, incontáveis benefícios.

A diminuição da idade penal não será capaz de impedir que amanhã sejam recrutados aqueles entre 14 e 16 anos de idade, ou mesmo os mais jovens. E a partir daí, qual será a simplista solução a ser proposta? "Por certo continuaremos o mesmo processo de redução sem discussão das verdadeiras causas a serem atacadas, quando então no Brasil até mesmo o recémnascido merecerá punição por ser um 'criminoso em potencial",". (BEZERRA, 2002, p. 255).

Para se nortear os aspectos da menoridade penal, faz-se mister o entendimento dos pontos que influenciam a jovens a aderir ao mundo da criminalidade. Serão realizadas análises que visam explanar causas, consequências e punições que envolvem jovens infratores.

O tema em questão traz uma grande polêmica que envolve volumosa parcela da sociedade, que buscam através de pressões aos legisladores, enrijecer as penas aos menores que cometerem infrações penais, o que na realidade, a mínima observância do sistema prisional brasileiro, evidencia o caos, e a calamidade em que se transformou. Resultado do velho costume da imposição da força, em vez do fomento/ investimento em educação, esporte, e lazer assegurados no Art. $6^{\circ}$ da CF.

Conforme os dizeres do célebre doutrinador Cezar Roberto Bitencourt (2011, p. 49): “A crise da pena de morte deu origem a uma nova modalidade de sanção penal: a pena privativa de liberdade, uma grande invenção que demonstrava ser meio mais eficaz de controle social". Tal crise no sistema carcerário brasileiro, mesmo com a criação de leis que versam sobre essa temática, evidencia a calamidade, e a falta de operacionalidade em que estão submersos.

O entendimento da precariedade do sistema prisional Brasileiro por si só já é um aspecto importante para se nortear as futuras decisões acerca dessa temática em evidência. Há hoje 704.395 presos para uma capacidade total de 415.960, um déficit de 288.435 vagas. Se forem contabilizados os presos em regime aberto e os que estão em carceragens da Polícia Civil, o número passa de 750 mil. (VELASCO, et al., 2019)

Cabe o debate, e uma consequente reflexão, de que a pena privativa de liberdade, e a passagem pelo sistema prisional, não deveria na realidade, ser uma tarja que persegue o indivíduo, manchando na maioria, o seu convívio em sociedade.

Afinal, evidencia-se certa distinção que dificulta progressivamente a oportunidade de reinserção ao mercado de trabalho, e ao convívio social, principal finalidade, mais que está em demasiado comprometida.

Dados mostram que as taxas de ressocialização dos presídios brasileiros são de quantificações ínfimas. Menos de um em cada cinco presos $(18,9 \%)$ trabalha hoje no país. O percentual de presos que estudam é ainda menor: $12,6 \%$. É o que mostra um levantamento do G1 dentro do Monitor da Violência, uma parceria com o Núcleo de Estudos da Violência (NEV) da USP e com o Fórum Brasileiro de Segurança Pública. (VELASCO, Et al., 2019)

Será que a aprovação, e o acirramento do debate sobre a menoridade penal não seria insistir no erro? Será que tais circunstâncias não necessitam de um enfrentamento diferente? Questões estas que serão debatidas em momento oportuno. 


\section{METODOLOGIA}

O tipo de pesquisa utilizada nesse trabalho científico é o exploratório, objetivando o entrelaçar de ideias que proporcione a aproximação do leitor com o problema, com vistas a torná-lo mais explícito ou a construir hipóteses. Utilizando fontes como livros, artigos e conteúdos da internet, visando sempre trazer as melhores percepções sobre o tema, de forma que provoque o aguçar da criticidade, favorecendo a sistematização dos fatores que envolvam a menoridade penal.

Para o desenvolvimento deste artigo foram utilizadas obras como "Curso de direitos fundamentais" (MARMELSTEIN,2014), "Código penal comentado" (NUCCI, 2010), já que tais obras trazem reflexões importantes acerca da menoridade, e a Constituição Federal Brasileira de 1988, sendo este último a base do trabalho, por estar essa temática envolvida em grandes questionamentos de índole constitucional.

No que tange ao tratamento dos resultados na produção deste trabalho cientifico, tem um caráter qualitativo, pois desenvolve-se tanto na interpretação de ideias compartilhadas por autores renomados, como também acerca de pensamentos e discursões socioculturais a respeito da subjetividade do tema, e a importância como deve ser tratado.

Todos os argumentos expostos no desenvolvimento do referido trabalho, busca sistematizar as informações de maneira clara, concisa, e fidedigna aos dados do encarceramento, fatores sociais, e as relações que envolvem o objeto em questão.

Assim, procuramos desenvolver o tema para embasar a sociedade da real situação da problemática observada no Brasil acerca da menoridade penal.

\section{MAIORIDADE PENAL NO BRASIL}

No Brasil, de acordo com o art. 228 da Constituição Federal, promulgada em 1988, são penalmente inimputáveis os menores de 18 anos, sujeitos às normas da legislação especial. (BRASIL, 1988)

Dessa forma, a idade mínima que permite-se a execução da pena na esfera penal é de 18 anos completos, assim, qualquer sujeito somente poderá ser penalizada pelo cometimento de crime no âmbito penal, quando comete uma ação ou omissão tipificada em lei e é maior de 18 anos.

Esta regra também é tipificada no código penal brasileiro, no qual define que o menor de 18 anos não comete crime, mas sim atos infracionais, vejam o que diz o artigo 27 do código penal brasileiro: “Art. 27 - Os menores de 18 (dezoito) anos são penalmente inimputáveis, ficando sujeitos às normas estabelecidas na legislação especial”. (BRASIL, 1940)

Dessa maneira, aquele que ainda não completou aquela idade, não tem, segundo presunção absoluta do ordenamento jurídico, o grau de maturidade para fazer-se penal- mente responsável. Pressupõe-se, por crité- rios político-criminais, seu desenvolvimento mental incompleto. No dia que completa essa idade - na data do seu aniversário de 18 anos -, cessa a inimputabili-dade, passando o mesmo a ser consi-derado plenamente imputável, salvo, é claro, se for portador de enfermidade mental. Na hipótese de não existência de documen- tação comprobatória da verdadeira idade de determinado indivíduo, deve o mesmo ser submetido ao exame de idade óssea. (JAPIASSÚ \& COSTA, 2015, Pág. 911-912).

A legislação brasileira é bem enfática e não deixa dúvidas acerca do exato momento da vida que as pessoas poderão sofrer com as sanções penais. Todavia, existe uma forte corrente no país que deseja que essa definição seja alterada, pois a violência no Brasil vem aumentando categoricamente, e muitas pessoas acreditam que essa consequência seja resquícios da impunidade dos menores infratores, havendo apenas a punição mais ostensiva aos maiores de idade.

Rogério Sanches Cunha (2016, Pág. 287), ao tratar dos elementos de culpabilidade apresenta as teorias adotadas pelo ordenamento brasileiro para definir critérios acerca dos sujeitos que podem sofrer sanções penais.

$\mathrm{O}$ referido autor discorre acerca de três teorias adotadas pelo ordenamento jurídico brasileiro sobre a inimputabilidade, sendo elas: o critério biológico, psicológico e o biopsicológico (CUNHA, 2016, p. 288).

No Tocante a inimputabilidade em razão da idade, haja vista haver outras excludentes de culpabilidade, Rogério Sanches explicita que a legislação brasileira adotou o critério biológico pois considera-se como fator determinantes para imputação de penal no âmbito penal a idade do sujeito ativo do crime, independentemente do infrator entender ou não o caráter ilícito de sua conduta (CUNHA, 2016, p. 291,).

Destarte, Víctor Gabriel Rodríguez discorre o tema sobre o tema, vejamos um excerto de sua obra:

A principal razão da presunção de inimputabilidade é a política criminal, como reconhecida pela doutrina desde Tobias Barreto. Atualmente, o ponto 23 da Exposição de Motivos da Nova Parte Geral do instituto faz referência clara à oportunidade de educação que deve ser dada ao jovem, ao convívio social 'sem sua necessária submissão ao tratamento do delinquente adulto, expondo-o à contaminação carcerária. Em outras palavras (...), é de dizer-se que a legislação penal decidiu consagrar ao jovem a oportunidade de estar afastado das garras do Direito Penal, ou ao menos daquele Direito Penal idêntico ao aplicado ao adulto, embora ele possa ser de 


\section{8, N. 1 (2020) I ISSN 2317-434X}

fato responsável por seus atos embora em última análise seu desenvolvimento mental não seja de fato incompleto. (RODRIGUEZ, 2010, p. 282).

Rogério Sanches Cunha conclui afirmando que a maioridade penal é alcançada no primeiro minuto do dia do aniversário de 18 anos do agente infrator, sendo prescindível alterações transitória e ficcionistas (CUNHA, 2016, p. 292,).

\section{MAIORIDADE PENAL EM OUTROS PAÍSES}

É recorrente que se façam comparações indiscriminadas de como as variantes da maioridade penal funcionam em determinadas sociedades, objetivando a influência de determinados aspectos, e tencionar o implante do procedimento que acha mais justo para o seu país. Entretanto, cada nação possui suas peculiaridades e afirmar isso não é um "clichê", pois é um fato verdadeiro e que deve ser observado nos mínimos detalhes para que não ocorram erros significativos para a população.

Destarte, diminuir a idade mínima para fins de punição na esfera penal não é tarefa das mais simples, pelo contrário, deve haver bastante estudo e análises de como proceder a um assunto tão sério e determinador na vida de qualquer pessoa, já que a exposição de menores a longo período no sistema carcerário brasileiro, não é e nem deve ser fácil por se tratar de um problema que está arraigado ao âmbito social vigente.

Conforme o Estatuto de Roma do Tribunal Penal Internacional (Decreto.$^{\circ}$ 4.388/02), precisamente em seu artigo 26, tal corte internacional não terá jurisdição sobre pessoas que ao tempo do cometimento do crime eram menores de 18 anos. (BRASIL, 2002)

Segundo o estudo, divulgado pelas secretarias Nacional de Juventude e de Políticas de Promoção da Igualdade Racial e pelo Programa das Nações Unidas para o Desenvolvimento (Pnud), entre 2005 e 2012, a população carcerária brasileira cresceu $74 \%$. No período, o número de presos subiu de 296.918 para 515.482. A maioria tem entre 18 anos e 29 anos, é negra e cumpre penas entre quatro e oito anos por crimes contra o patrimônio ou ligados às drogas. (RODRIGUES, 2015)

Faz-se mister a análise da média da maioridade penal no mundo, tendo como base 197 países.

As médias de maioridade penal para as duas fontes utilizadas são bastante semelhantes. Enquanto a média estimada a partir dos dados da Grand Valley State University (2012) é de 18,29, para os dados de Hazel (2008) é de 17,76 anos, ou seja, uma diferença residual de 0,53. Cingapura segue com a menor maioridade penal (12), mesmo depois de introduzir a nova fonte de dados, da mesma forma a China (25) se mantém com a maioridade penal mais alta. (LINS, FIGUEIREDO FILHO \& SILVA,
2016 Pág. 125)

A Alemanha recentemente diminuiu a maioridade penal para os 16 anos de idade, todavia essa mudança não perdurou por muito tempo, pois, mais uma vez, os índices de violência não diminuíram por causa da mudança na legislação que trata o assunto. (BELLINI, 2016)

Por outro lado, países considerados seguros, com baixos índices de violência não possuem maioridade penal baixa, como Nova Zelândia que é considerado o país mais seguro do mundo e Noruega que também encabeça a lista de mais seguros. Esses e outros países tem estabelecimento a maioridade penal nos 18 anos de idade, como é hoje no Brasil.

Levantamento da Unicef (Fundo das Nações Unidas para a Infância) realizado em 2009 com 54 países mostra uma grande variação da maioridade penal, que oscila entre os 12 e 21 anos no mundo. Para o Comitê dos Direitos das Crianças, da ONU, a maioridade deveria ocorrer apenas após os 18 anos. (ALVARES, 2015)

A diferença está na qualidade de vida, já que os países que investem em educação, saúde e segurança acabam por economizar na construção de presídios, pois a tendência é que eles esvaziem com o investimento nos setores essenciais, o que transforma a população.

A mínima observância de tais aspectos notabiliza pontos cruciais como investimento social e fomento em oportunidades, como saídas cabíveis que possibilitam a reinserção de jovens, e a um real impacto de suas ações positivas.

\section{VIOLENNCIA E MENORES DE 18 ANOS}

A violência no Brasil está exacerbando praticamente todos os limites, e escraviza a sociedade, de forma a suprimir direitos fundamentais que devem ser considerados como estruturantes da temática moderna; entre eles estão o direito de ir e vir, que está sendo cada vez mais cerceado pelo medo e a violência.

Percebe-se a chegada a um ponto de não existir mais sensação de segurança em grande parte do país, enorme parcela da população vive com medo e não é para menos, a cada instante novas notícias de crimes sendo praticados, pessoas sendo mortas e o Estado sendo ineficaz nesse combate contra a violência. Infelizmente, pois quem diretamente sofre com esse problema é a população.

No Brasil, portanto, por questões de política criminal, optou-se por um critério rígido. É certo, contudo, sustenta-se uma revisão dessa regra, visto que, em razão da evolução da sociedade, o jovem brasileiro adquire, em idade inferior aos dezoito anos, a capacidade real de compreensão de sua conduta, ao menos para os fatos 
antijurídicos mais graves, ou seja, aqueles arraigados culturalmente desde tenra idade (homicídio, lesões corporais, estupro etc.). (JAPIASSÚ \& COSTA, 2015, Pág. 912)

Muitas pessoas indicam que esse aumento na violência é consequência da idade mínima de 18 anos para a punição a quem comete delitos penais, pois a mídia publicita dados com altos índices de ilícitos cometidos por menores e que as punições são insuficientes, e incompatíveis com o delito cometido, dessa forma, acreditam que tal realidade seja um incentivo para que se multipliquem tais atos, menores cometendo delitos e que não haja a devida aplicação das sanções.

Entretanto, dados científicos mostram o contrário, vejamos:

Os delitos realizados por pessoas com mais de 18 anos representam mais de $90 \%$ do total. Os dados de Adorno, Bordini e Lima (1999) indicam que os homicídios cometidos por adolescentes correspondem a 1,3\%. Para Sankievicz. (2007), "a preocupação com a violência juvenil nas sociedades modernas é desproporcional à gravidade e à incidência dos atos infracionais praticados pelos adolescentes" (Sankievicz, 2007, p. 7). (LINS, FIGUEIREDO FILHO \& SILVA, 2016 Pág. 120)

Ao conferirmos esses dados, percebemos que o número de jovens que praticam homicídios é bem menor com relação ao público adulto.

Outro ponto a ser destacado é que os jovens que cometem delitos análogos a crime são punidos de acordo com o Estatuto da Criança e do Adolescente (ECA), nesse diapasão, é oportuna a leitura de Olympio de Sá Sotto Maior Neto, Procurado de Justiça do Estado do Paraná:

Em outro aspecto, levando-se em conta que os adolescentes são pessoas em peculiar fase de desenvolvimento marcada por crise determinada pela complexa passagem do mundo infantil para o adulto (todos, de qualquer maneira, ainda não devidamente socializados), vale lembrar que o Estatuto da Criança e do Adolescente já prevê resposta, de caráter sócio-educativo, para a prática de atos infracionais (não contemplando qualquer regra que possa ser traduzida em "garantir impunidade" aos adolescentes, tanto que, para os casos mais graves, estabelece inclusive medida privativa de liberdade). Além da sua submissão ao Estatuto da Criança $e$ do Adolescente, prevista no art. 228, da Constituição Federal, constituir cláusula pétrea (portanto, insus-cetível de modifi-cação por emenda constitu-cional), tem-se que as medidas sócio-educativas objeti-vam o resgate social do adolescente autor de ato infracional e não a entrega definitiva do mesmo para o mundo da criminalidade." (NETO, 2016)

Porém, mesmo com os trabalhos científicos mostrando a realidade acerca do baixo número de crimes praticados por menores comparando com os adultos, grande parte da sociedade acredita que reduzindo a maioridade penal, os índices de violência também podem diminuir, não é à toa que isto já foi tema de várias $\mathrm{PEC}$ 'S ( Proposta de Emenda Constitucional) como a 74/2011, 33/2012, 21/2013 e 115/2015.

Em consequência de tamanhas divergências sobre maioridade penal, resta a dúvida sobre a constitucionalidade de tais propostas de emenda a constituição. O STF já reconheceu a existência de clausulas pétreas fora do art. $5^{\circ}$, o que abriu espaço para interpretações extensivas que abrangem vários outros artigos da $\mathrm{CF}$.

Tais emendas buscavam a alteração do art. 228 $\mathrm{CF} / 88$, que diz em sua integralidade, "São penalmente inimputáveis os menores de dezoito anos, sujeitos às normas da legislação especial." (BRASIL, 1988). A dúvida quanto a sua modificação está diretamente relacionado a sua qualidade como cláusula pétrea ou não, razão esta que pode dificultar tal medida. A devida análise do artigo mostra que a alteração da idade para a responsabilização criminal, não é instrumento para abolir tal direito.

Outro mito que profere na sociedade é quando se afirma que o jovem infrator não sofre punição. Porém, dáse ciência que esses jovens respondem por um sistema especial e sofrem sanções que são tipificadas no ECA (Estatuto da Criança e do Adolescente). Portanto, é um erro falar sobre a impunidade para aqueles infratores. $\mathrm{O}$ que pode ser debatido é se sua real aplicação é suficiente em comparação à conduta praticada.

O ECA funciona para que os jovens sejam reintegrados na sociedade, para isso os menores infratores são submetido à internação pela FEBEM, sendo lhe imputado punição de privação da liberdade por no máximo três anos. Todavia, há outros tipos de sanções educativas para estes jovens.

É necessário o entendimento de que simplesmente largar esses jovens no sistema prisional brasileiro seria um ato bastante complicado e arriscado, pois sabemos da superlotação, da falta de segurança e qualidade das prisões nacionais, que a cada dia ficam mais nefasto, e insuficiente para conseguir cumprir sua missão de ressocialização como se verifica no art. $1^{\circ}$ da LEP (Lei de Execução Penal) "A execução penal tem por objetivo efetivar as disposições de sentença ou decisão criminal e proporcionar condições para a harmônica integração social do condenado e do internado.” (BRASIL, 1984).

Entretanto, as FEBEM's passam por problemas de infraestrutura semelhantes, o poder público negligencia essas institucionais que são fundamentais para a sociedade, analisando do ponto de vista que todo preso ou 
jovem internado, caso não sucumba à violência dentro dessas instituições, deverá retornar a sociedade, então é fundamental que haja uma devida recuperação e uma consequente ressocialização para que estes possam voltar ao convívio social e não retomem a vida de crimes, fator que propicia a criação de um ciclo vicioso.

Ademais, os jovens infratores por não receberem um tratamento adequado, apesar de ter contra sí restrições trazidas pelo ECA, continuam a praticar delitos.

\section{"Essa onda crescente de violência praticada por menores faz com que, a toda hora, o sistema de internação seja repensado. Tal como ocorre com as penitenciárias, os menores são jogados, como é o caso do Brasil, em instituições que não os recuperam, que os tratam com crueldade, de forma desumana e degradante." (GRECO, 2015).}

É essencial que o Estado cumpra seu dever e consiga levar esse jovem infrator para o caminho da educação, e não o contrário. Todavia, enquanto houver essa falha de ressocialização desse grupo, a internação ou outras medidas socioeducativas continuarão ineficazes.

Portanto, é dever do Estado investir não somente em quantidade, e sim em qualidade, buscando a criação de programas que sejam efetivamente capazes de integrar os jovens na sociedade e tira-los do mundo do crime, para com isso realmente darem uma nova chance, investindo numa nova roupagem no enfrentamento à criminalidade, desmistificando a ideia da imposição da força, de maneira que não propicie a "formação de jovens para o mundo do crime".

\section{COEFICIENTES QUE EXPÕEM O JOVEM À CRIMINALIDADE}

Quando se fala em diminuição da maioridade penal, a priori, devem-se analisar vários outros problemas que marginalizam os jovens, e os tornam cada vez mais frágeis, ou propensos como o queira, a entrada no mundo das drogas, do crime, entre outros que poderiam facilmente ser elencados, mas que não diferente dos outros, expõe o jovem que na maioria é pobre e negro, a circunstâncias de extrema necessidade.

Questões como a precariedade do sistema de educacional no Brasil é fator decisivo para uma possível inserção de adolescentes na vida de crimes. Como se sabe, boa parte das escolas públicas contam com baixo investimento do Estado, e sofrem com a corrupção, em que dinheiro que deveriam ser investidos na educação, acaba sendo desviado para o bolso de pessoas que se utilizam da máquina pública como facilitador para o recebimento de vantagens. Dessa forma, a educação não consegue cumprir seu papel de também formar para a vida, e acabam negligenciando essa formação.

Quando se acumulam fatores como famílias despreparadas, em que o âmbito familiar não contribui para que os filhos sigam um caminho longe dos crimes, em consonância com o despreparo das escolas, que não conseguem atrair as crianças e adolescentes, percebe-se a fragilização desse grupo tendo em vista circunstâncias sociopolíticas e históricas, findado por seguir o caminho mais fácil, pois a criminalidade está no dia a dia, porém, que não é o mais correto.

A fragilidade do investimento em esportes, uma boa saída para um enfrentamento com a marginalização, também é muito precária. Portanto, faz-se mister o entendimento de que a criação de políticas públicas com a finalidade de inclusão, devem ser repensadas, e verdadeiramente efetivadas tendo em vista o grau de importância, pois são remédios fundamentais na luta contra a inserção de jovens na criminalidade. Afinal, já sabemos que nem sempre o enfrentamento, a imposição da força, é suficiente, e eficaz, para se mudar a realidade que hoje é caótica.

A insistência na menoridade penal é estruturada por velhos erros que apenas buscam a imposição da força como principal meio para conseguir uma pequena redução dos crimes, e coloque pequeno nisso, pois nunca chegará a combater de forma efetiva, e alcançar resultados que agradem a sociedade. Tal atitude servirá apenas para maquiar o problema, e esconder a inércia dos legisladores.

\section{CONSIDERAÇÕES FINAIS}

Nesse sentido, podemos observar que a redução da maioridade penal defendida por muitos, é inconstitucional, haja vista está em nosso ordenamento maior, Constituição Federal. Ademais, acreditamos que tal redução poderá ser ineficaz, pois os maiores que cometem crimes são duramente punidos pela legislação brasileira e nem por isso o número de delitos é diminuto no Brasil.

Assim, invés de falarmos em punições exacerbadas faz-se necessário investir em educação, a fim de inserir jovens e adolescentes em seu habitat, ou seja, em um ambiente de ensino. Uma educação integral, e de qualidade, pode transformar uma sociedade. Pois as péssimas condições de vida, educação de má qualidade, baixa infraestrutura nas escolas e falta de políticas de incentivo para esse público específico, pode gerar graves consequências ao convívio social.

Portanto, apenas reduzir a idade penal provavelmente não será o suficiente, já que temos ciência de todo o complexo de problemas que está englobado o contexto brasileiro. Dessa forma, devemos cuidar para que esses jovens não se perpetuem nos crimes, mas sim que se recuperem com o auxílio do Estado, através de 


\section{8, N. 1 (2020) I ISSN 2317-434X}

políticas públicas voltadas para uma eficaz recuperação e ressocialização, sem que seja necessário que estes jovens passem pelo sistema prisional brasileiro, que é no sentido literal da palavra, desumano.

\section{REFERÊNCIAS}

ALVARES, R. (17 de Abril de 2015). De acordo com Unicef, maioridade penal no mundo oscila entre 12 e 21 anos. Acesso em 12 de Agosto de 2019, disponível em UOL:https://noticias.uol.com.br/internacional/ultimasnoticias/2015/04/17/polemica-no-congresso-idade-paramaioridade-penal-nao-chega-a-consenso-em-variospaises.htm

ALVES, Thalitiane de Carvalho. A maioridade penal no ordenamento jurídico brasileiro. In: Âmbito Jurídico, Rio Grande, XVII, n. 126, jul 2014. Disponível em: $<$ http://www.ambitojuridico.com.br/site/?n_link=revi sta_artigos_leitura\&artigo_id=15026>. Acesso em out 2017.

BELLINI, P. (30 de Outubro de 2016). Como funciona a maioridade penal em outros países? Acesso em 12 de Agosto de 2019, disponível em Super Interessante: https://super.abril.com.br/historia/como-funciona-amaioridade-penal-em-outros-paises/

BEZERRA, apud LOCHE, Adriana Alves; LEITE, António J. Maffezoli. Sociologia Jurídica. Redução da Imputabilidade Penal: ineficácia social e impossibilidade constitucional. Revista Brasileira de Ciências Criminais. São Paulo: Revista dos Tribunais, ano 10, n. 37, jan./mar. 2002, p. 255.

BRASIL. Constituição da República Federativa do Brasil: promulgada em 5 de outubro de 1988.

BRASIL. Decreto-Lei 2.848, de 07 de dezembro de 1940. Código Penal. Diário Oficial da União, Rio de Janeiro, 31 dez. 1940.

BRASIL. (s.d.). DECRETO $\mathrm{N}^{\circ}$ 4.388, DE 25 DE SETEMBRO DE 2002. Acesso em 11 de Agosto de 2019, disponível em

Planalto:http://www.planalto.gov.br/ccivil_03/decreto/20 02/D4388.htm

BRASIL. Lei $\mathrm{n}^{\circ} 7.210$, de 11 de julho de 1984. Lei de Execuções Penais. Brasília.

BITENCOURT, Cezar Roberto. Falência da Pena de Prisão - Causas e Alternativas. 4. ed. . São Paulo: Saraiva, 2011.
CUNHA, R. s. (2016). Manual de Direito Penal (Vol. Único). Salvador: Juspodivm.

CURY, M. et al. Estatuto da criança e do adolescente comentado: comentários jurídicos e sociais.5. ed. rev. e atual. São Paulo: Malheiros, 2002.

ERIKSON, E. Identidade, juventude e crise. Rio de Janeiro: Guanabara Koogan, 1987.

FREITAS, Juarez. Sustentabilidade: direito ao futuro. 2. ed. Belo Horizonte: fórum, 2012.

GRECO, R. (2015). Reflexões sobre a redução da maioridade penal. Acesso em 12 de Agosto de 2019, disponível

em Jusbrasil:https://rogeriogreco.jusbrasil.com.br/artigos/178 724226/reflexoes-sobre-a-reducao-da-maioridade-penal

JAPIASSÚ, C. e., \& COSTA, R. D. (2015). Discussão em torno da maioridade penal: um debate entre políticas públicas, simbolismos e neurociência. Revista direito da cidade, 95-921.

LINS, Rodrigo; FIGUEIREDO FILHO, Dalson and SILVA, Lucas. A redução da maioridade penal diminui a violência? Evidências de um estudo comparado. Opin. Publica [online]. 2016, vol.22, n.1, pp.118-139.

MARMELSTEIN, G. (2014). Curso de Direitos Fundamentais $\left(5^{\circ} \mathrm{ed}.\right)$. Atlas.

NASCIMENTO, Priscila Braga. A inimputabilidade penal do menor de idade. Revista Jus Navigandi, ISSN 15184862, Teresina, ano 20, n. 4458, 15 set. 2015. Disponível em:<https://jus.com.br/artigos/34052>. Acesso em: 13 out. 2017.

NETO, O. d. (2016). Os adolescentes que estiveram em conflito com a lei. Acesso em 12 de Agosto de 2019, disponível em Ministério público do estado do Paraná: http://www.crianca.mppr.mp.br/modules/conteudo/conte udo.php?conteudo=253

NUCCI, Guilherme de Souza. Código penal Comentado. $10^{\mathrm{a}}$ Ed. São Paulo: Revista dos Tribunais, 2010.

RODRIGUES, A. (04 de Junho de 2015). Modelo 
carcerário brasileiro não diminui criminalidade, avaliam especialistas. Acesso em 12 de Agosto de 2019, disponível em Agência

http://agenciabrasil.ebc.com.br/geral/noticia/2015-

06/modelo-carcerario-brasileiro-nao-reduz-criminalidade

RODRIGUEZ, V. G. (2010). Fundamento e Direito Penal Brasileiro. São Paulo: Atlas.

SADA, J. (30 de Novembro de 2016). Como o mundo vê a questão da maioridade penal. Acesso em 10 de Agosto de 2019, disponível em Fundação Telefonica: http://fundacaotelefonica.org.br/promenino/trabalhoinfan til/noticia/como-o-mundo-ve-a-questao-da-maioridadepenal/

SENADO, A. (12 de Agosto de 2016). Especialistas: redução da maioridade penal é inconstitucional e não resolve violência. Acesso em 10 de Agosto de 2019, disponível

em

Senado

Notícias: https://www12.senado.leg.br/noticias/materias/2016/08/1 1/especialistas-reducao-da-maioridade-penal-einconstitucional-e-nao-resolve-violencia

VELASCO, c. ,. (26 de Abril de 2019). Super Lotação Aumenta e Números de Presos Provisórios Sobe no País. Acesso em 12 de Agosto de 2019, disponível em G1: https://g1.globo.com/monitor-daviolencia/noticia/2019/04/26/superlotacao-aumenta-enumero-de-presos-provisorios-volta-a-crescer-nobrasil.ghtml

VELASCO, c. e. (26 de Abril de 2019). Menos de 1/5 dos presos trabalha no Brasil; 1 em cada 8 estuda. Acesso em 12 de Agosto de 2019, disponível em G1: https://g1.globo.com/monitor-da-

violencia/noticia/2019/04/26/menos-de-15-do-presostrabalha-no-brasil-1-em-cada-8-estuda.ghtml 